\title{
ON-TIME PERFORMANCE ANALYSIS AND ISSUES TO KEEP CUSTOMERS SATISFIED (CASE STUDY: DOMESTIC FLIGHTS OF GARUDA INDONESIA IN SOEKARNO-HATTA INTERNATIONAL AIRPORT)
}

\author{
Juliater Simarmata ${ }^{1}$, Yulianti Keke ${ }^{2}$, Ridzeki Akbar ${ }^{3}$ \\ 1. STMT Trisakti, 2. STMT Trisakti, 3. STMT Trisakti \\ Email : juliaters@gmail.com, yuliakeke@gmail.com
}

\begin{abstract}
Garuda Indonesia, as the first airline that is moving to Terminal 3 is facing a serious issue regarding on-time performance as the new terminal is not completely prepared for operations. This research is conducted using a comparative method to compare the on-time performance of Garuda Indonesia in the first half of 2016 (January to June 2016) and the second half of 2016 (July to December 2016) and point out the issues in the Terminal 3 of Soekarno-Hatta International Airport where Garuda Indonesia's domestic flight operations is conducted.

Keywords: airline, on-time performance, airport, terminal, airline operations
\end{abstract}

\section{Introduction}

The development of the aviation industry in the recent years is growing significantly. This is caused by the rapid growth of demand for the service. The number of airline passengers is predicted to grow by $15 \%$ during the year 2016 (source: The Indonesia National Air Carriers Association (INACA). In Indonesia alone, the main International hub - which is Soekarno-Hatta International Airportis already having capacity issues and in a dire need for expansion. The purpose of the air transportation system is the cost effective, rapid, safe transportation of passengers and cargo. In this way the air transportation system is a significant "engine" of the national economy and provides a service that cannot be achieved by other modes of transportation (Duke and Torres 2005). Garuda Indonesia, as Indonesian one and only flag carrier is setting a high standard on service. In OnTime Performance percentage, Garuda Indonesia has set the target for OTP at 85\% and have been achieving a very good score so far. But even so, as the growth of airline service user is so rapid, not only Garuda Indonesia need to increase service capacity (e.g. Aircrafts) they also need a bigger "home" in order to provide such services.

In the recent years, PT Angkasa Pura II's very own Soekarno-Hatta International Airport have been developing a new terminal called Terminal 3 to solve the airport's capacity issue. Before the Terminal 3 Ultimate is opened, there are small portion of the Terminal 3 that is opened earlier to accommodate numbers of carriers. 
Later in August 2016, The Terminal 3 Ultimate (Now only known as Terminal 3) is established and operated, with Garuda Indonesia as the first carrier to operate in the new terminal. Garuda Indonesia have previously operating in Terminal 2 in Soekarno-Hatta International Airport (Terminal 2E for international flights and Terminal $2 \mathrm{~F}$ for domestic flights). Being the first airline to operate is not always beneficial as there are many problems arising from the new terminal. As a consequence, the percentage of Garuda Indonesia's On-time Performance is dropping significantly on August 2016 especially at CGK station because it turns out that the new terminal is not completely ready to operate. Aircraft mechanical problems, severe weather, crew sickness, airport curfews, and security are among the problems that force an airline to delay or even cancel their regular published flights. On an average day in the United States, approximately $15-20 \%$ of all flights experience significant delays (more than 15 minutes) and approximately $1-3 \%$ of all flights are cancelled, while passenger flow is a process that a passenger must undergo when they are going to depart (Departure flow) or arrive (Arrival flow) (Matsuo, Hatori et al. 2010). Figure 1.1 shows the conventional model of passenger flow in airports.

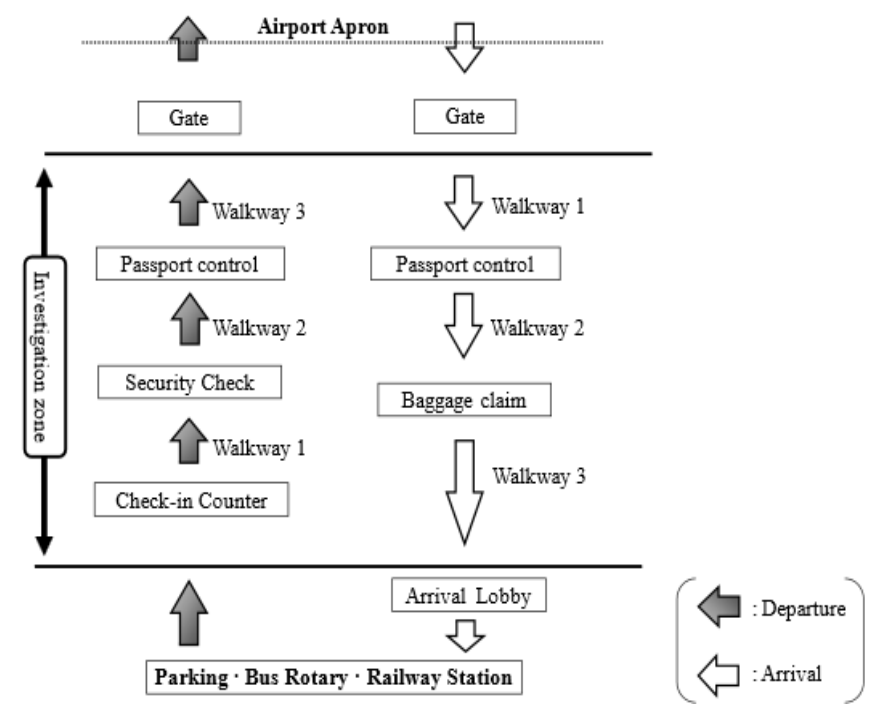

Figure 1.1. Passenger flow in airport terminals.

Baggage handling is another aspect of airport service, Departing baggage, coming either from the check-in desks, cross x-ray machines (all baggage or a fraction, according to the airport rules) and possibly further inspection apparels and/or operators if necessary or convenient, then they are sorted and sent to the right 
pier to be loaded; particular (irregular, oversize, etc.) items are treated apart. Arriving baggage are unloaded, moved to the inbound area, sorted and then sent either to the baggage claim area (arriving baggage), or to the transit baggage area (transit baggage), to be possibly relabeled and finally moved to join departing baggage (Brunetta and Romanin-Jacur 2004). Figure 1.2 and Figure 1.3 shows the model of the baggage flow in an airport.

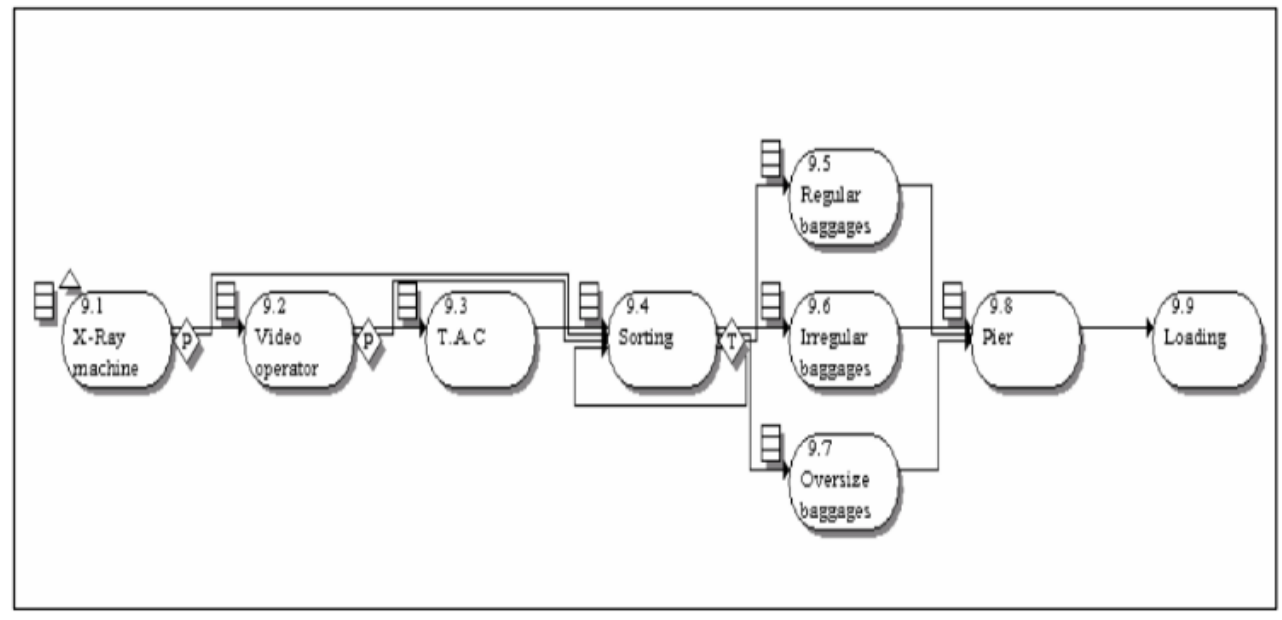

Figure 1.2. Baggage handling for departing baggage.

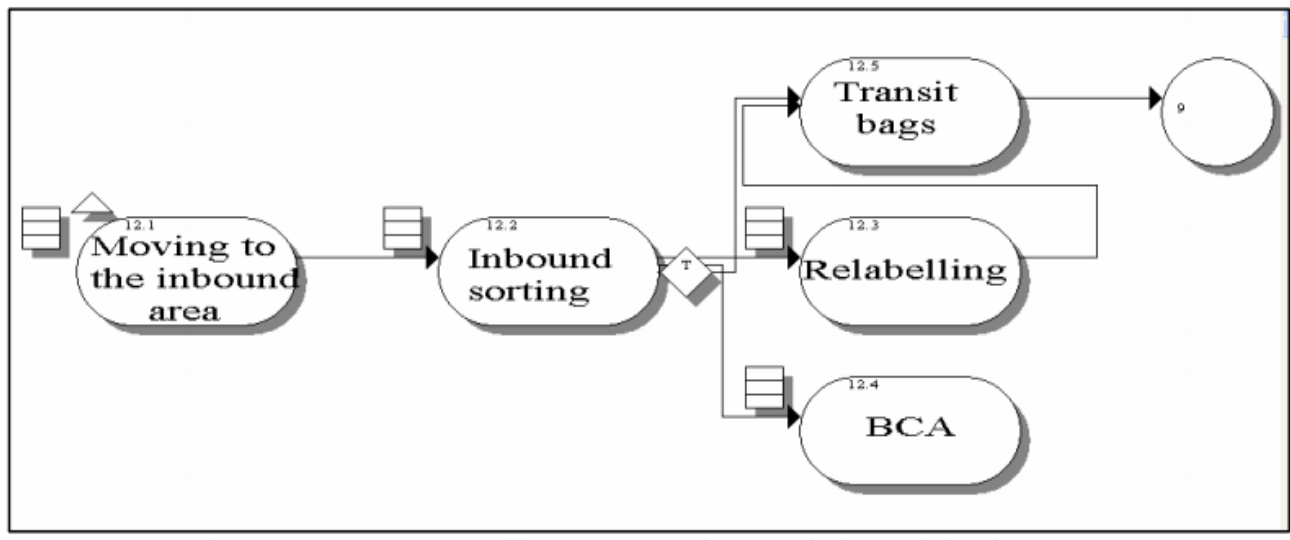

Figure 1.3. Baggage handling for arriving baggage.

The problems of Garuda Indonesia in Soekarno-Hatta International Airport is about the growth of passenger and the capability of the airport to accommodate them while still having all aspects of services working smoothly. And this research is going to identify and explain the cause of delay in Soekarno-Hatta International Airport. 


\section{Method}

There are enduring methodological problems in comparative research (Mills 2006) several key problems include:

1. Case selection, unit, level, and scale of analysis

2. Construct equivalence

3. Variable or case orientation

4. Issues of causality

Comparative method is a research methodology that aims to make comparisons across different situations (for example: one subject between different countries, between different cultures, between different time span, etc.) (Lor 2011). This research will compare the situations of Garuda Indonesia's operation, specifically delays that is highly related to on-time performance between different situation which is during their operation in Terminal 2 and Terminal 3. Table 2.1 is an example of comparison table used to compare the data.

Table 2.1. Comparison Table.

\begin{tabular}{|c|c|c|c|}
\hline \multicolumn{4}{|c|}{ Terminal } \\
\hline & & & \\
\hline & & Range & Count \\
\hline \multirow{11}{*}{ 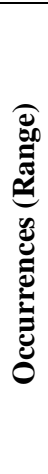 } & $0-199$ & & \\
\hline & $200-399$ & & \\
\hline & $400-599$ & & \\
\hline & $600-799$ & & \\
\hline & $800-999$ & & \\
\hline & 1000-1199 & & \\
\hline & $1200-1399$ & & \\
\hline & $1400-1599$ & & \\
\hline & $1600-1799$ & & \\
\hline & 1800-1999 & & \\
\hline & $>2000$ & & \\
\hline
\end{tabular}

Descriptive research is a research method that involves gathering data that describe events and then organizes, tabulates, depicts, and describes the data collection (Glass and Hopkins 1984). Descriptive researches often uses visual aids such as graphs and charts to aid the reader in understanding the data distribution. Because the human mind cannot extract the full import of a large mass of raw data, descriptive statistics are very important in reducing the data to manageable form. A descriptive study might employ methods of analyzing correlations between multiple variables by using tests in order to identify factors of causality of an event. 


\section{Discussion and Result}

\section{Data Analysis}

Using the comparison table and by grouping delay factors based on delay codes that Garuda Indonesia uses, the following are the processed data presented in charts. 1. OTP Fluctuations in 2016

This section will show the fluctuation of Garuda Indonesia's domestic flights ontime performance in Soekarno-Hatta International Airport (CGK) in the operational year 2016 and compare it to the company standard OTP target of 85\%. The fluctuations is shown in the Chart 3.1:

Chart 3.1. OTP Fluctuations in 2016.

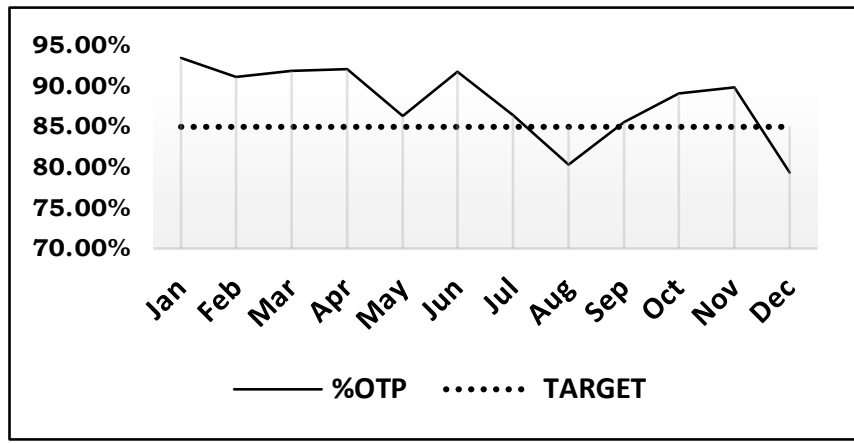

The graph shows the trend of Garuda Indonesia in the year 2016 is degrading with the lowest point at $79.36 \%$ at December 2016. The on-time performance is also having a down-spike on August 2016 at $80.35 \%$, all on the second half of 2016.

2. Comparison of Delay Cause Percentage

The following Chart 3.2 are the comparison of delay causes between the first half and the second half of 2016 in percentage:

Chart 3.2. Delay Contribution Comparison.

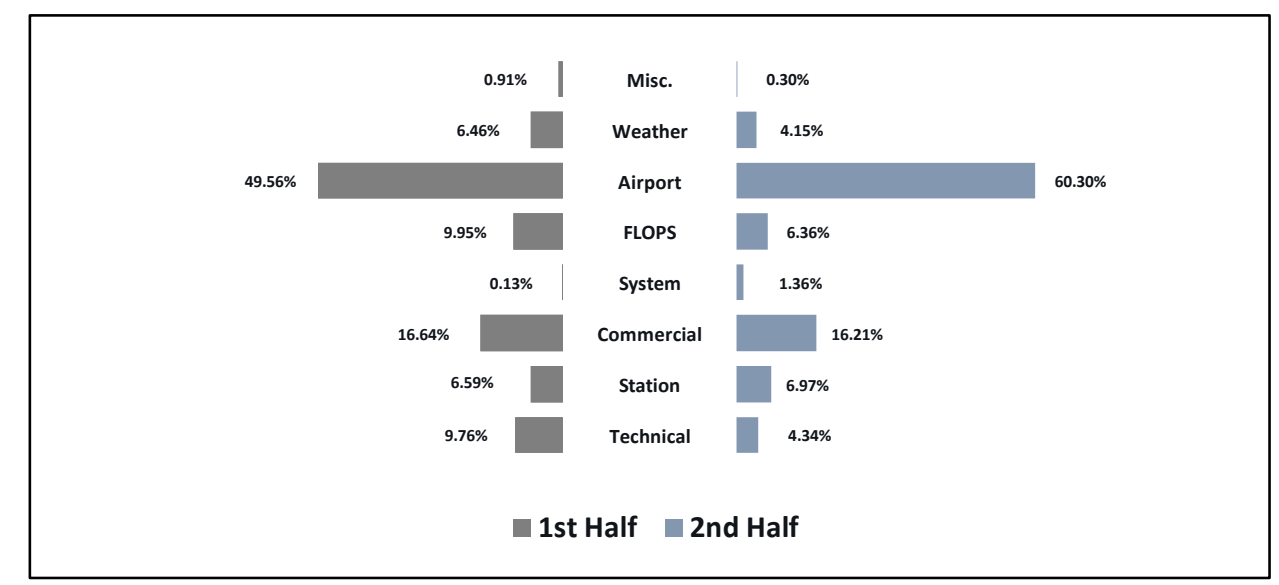


From the recapitulated data above, the percentage of delay caused by airport is increasing significantly from $49.56 \%$ on the first half of 2016 to $60.30 \%$ on the second half, which is roughly $10 \%$ increase. Average OTP in the first half is $91,16 \%$ and average OTP in the second half is $85,14 \%$, with a total of $56,56 \%$ or 4978 delays caused by airport in the entire year 2016 rise must indicate that some issues is arising in Terminal 3.

\section{Top 3 Delay Contributor}

The top three delay contributor is an additional data used to point out how much airport delay occurrences compared to other delay factors. The top 3 delay contributor is shown in Chart 3.3.

Chart 3.3. Top 3 Delay Contributor.

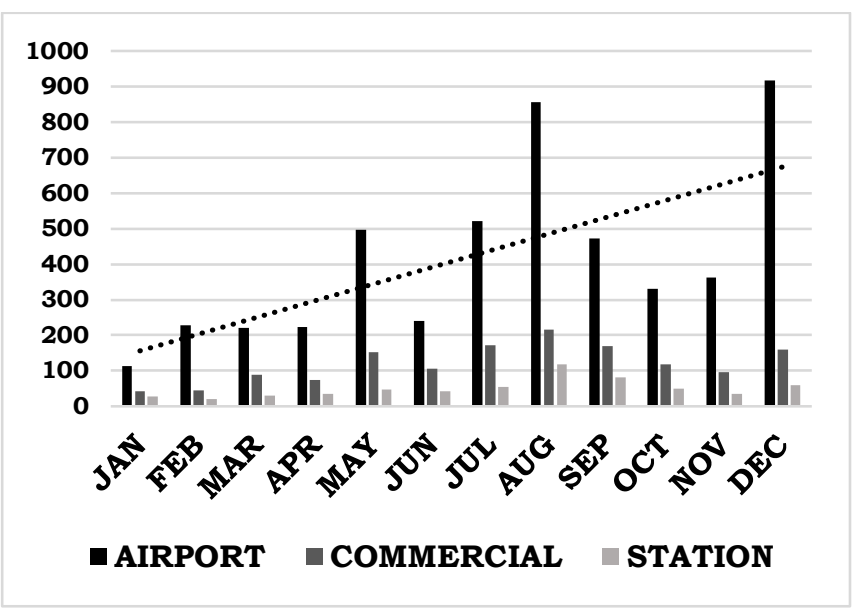

The graph above shows the top 3 delay contributors which is airport, commercial and station handling delay. From the trend line it can be seen that the fluctuation of commercial and station handling delay is rather constant and in a far lower number compared to airport delay which is unstable, spiky and relatively high in number. The graph also shows that airport delay have spikes in the month August to December 2016 and consecutively causing the drop in the average on-time performance percentage in the second half of 2016. Based on this analysis, the discussion will focus on the cause of airport delays in the second half of 2016. The actual issue that is happening on Terminal 3 will also be investigated based on this analysis. The other delay factors aside from airport delay will be considered minoralbeit not neglected — based on the data that airport delay contributed more than 50\% of all delays in 2016 and impacting on-time performance in biggest amount compared to other factors. Cancelled and rescheduled flights will not be investigated as well due to the facts that the number is rather small and consistent each month 
compared to other delay factors, and even though it is one of the variables in the ontime performance formula, the change that cancelled and rescheduled flights can make to on-time performance percentage will be insignificant.

4. Observed Issues in Airport

Airport services and facilities covers a wide variety of aspects. The airport area itself is divided by two categories, the airside and the landside. The airside facilities includes airfield design, airfield capacity, airfield delay, and air traffic management. While airport landside covers passenger building, baggage handling, passenger hotspots, ground access and distributions, space requirements for passenger areas, and systems which includes an IT-based control system and mechanical system (Neufville and Odoni 2013).

Based on field observation, issues found in Terminal 3 of Soekarno-Hatta International Airport that is causing delays in Garuda Indonesia domestic flights is as follows:

\section{Gate Capacity Differences}

Capacity Gap is a difference between terminal capacity before and after moving the operation terminal of Garuda Indonesia from Terminal 2 to Terminal 3. The dimension for airport capacity is wide as it covers several factors such as parking stands, terminal gates, runway capability, etc. Therefore, researcher is going to limit the dimension of airport capacity in this paper to terminal gates number. By concluding that the domestic flights in Soekarno-Hatta International airport is conducted in Terminal 2F during the first half of 2016, and in Terminal 3 during the second half of 2016, a gate capacity comparison will be shown below.

There are 7 gates in Terminal 2F, in which each gate can accommodate a remote boarding (using bus to transport passenger to an aircraft parked in remote area). With that calculation, Terminal $2 \mathrm{~F}$ is capable to accommodate 14 boarding with 14 aircraft at the same time.

Terminal 3 can only accommodate 5 gates during the second half of 2016, which is gate $11,12,13,14,15$ and 2 gates for remote boarding on Gate 13 and Gate 14 . This condition gives Garuda Indonesia a capability of 7 boarding with 7 aircraft at the same time, which is half the capability of Garuda Indonesia in the previous terminal 2F. This explains the cause of delay in the second half of 2016 because the previous number of domestic flights need to be adjusted to the new terminal gate. An increased number of delay is unavoidable with that sudden change of gate 
availability. The comparison of Gate availability in terminal 2 and terminal 3 is shown in Figure 4.1

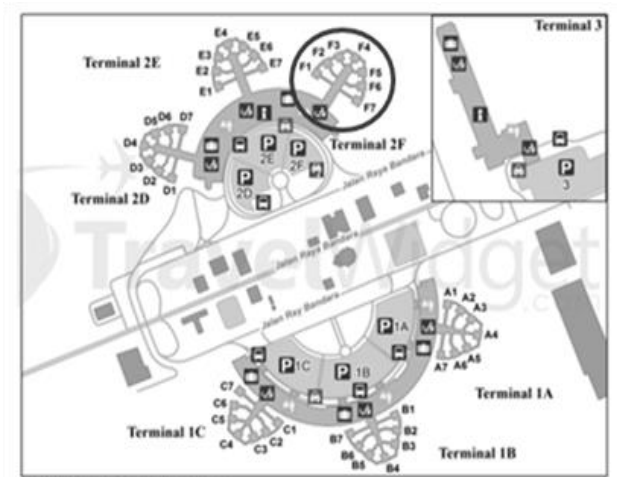

Soekarno-Hatta International Airport Terminal 2F (January to June 2017)

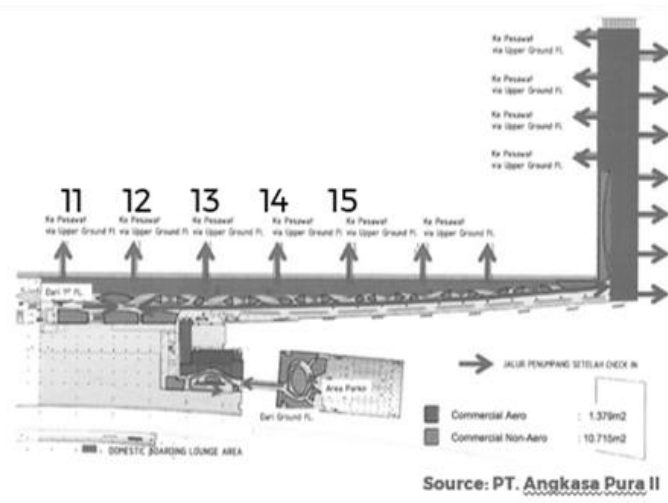

Soekarno-Hatta International Airport Terminal 3 (July to December 2017)

Figure 4.1. Comparison of Gate Capacity

6. Flight Information Display System (FIDS)

FIDS or Flight Information Display System is a system which collects all the data regarding flights and showing flight information to both passenger and staffs in the airport area in form of digital screens and/or printed documents.

There are 4 (Four) discrepancies of information from FIDS in Soekarno-Hatta International Airport:

1) Boarding Pass

In the day of the opening, as Garuda Indonesia need to adjust the schedule with the terminal gates in Terminal 3, the arrival gate is not written in passenger boarding pass because the gate is yet to be assigned for an aircraft or a flight. This is causing confusion for passenger.

2) Boarding Area

The information screen in boarding area is not showing the correct information about flight and its designated gates, causing confusion to passenger.

3) Baggage Claim Area

The information screen in Baggage Claim Area is not showing the correct information regarding flight and its designated carousel, causing passenger to queue on the wrong carousel line and/or picking up the wrong baggage.

4) Baggage Make-Up Area 
Mismatched information occurs in Baggage Make-Up area. The baggage that is delivered to the carousel does not match the baggage tag. The baggage need to be rearranged manually to avoid it to be loaded to the wrong aircraft.

These errors in the Flight Information Display System is the cause of the increase in system delay during operational year 2016 from $0.13 \%$ in the first half to $1.36 \%$ in the second half.

\section{a. Baggage Handling System}

The baggage handling system (BHS) in Terminal 3 is functioning as a scanning and sorting device, it is used to scan the insides of the baggage to identify dangerous goods, as well as sorting the baggage, delivering it to the designated carousel in which the baggage will be loaded to an aircraft. However, this scanning and sorting is causing prolonged delivery to the carousel due to the increased layers in the scanning and sorting process. Moreover, the conveyer belt transporting the baggage have several conditions for baggage

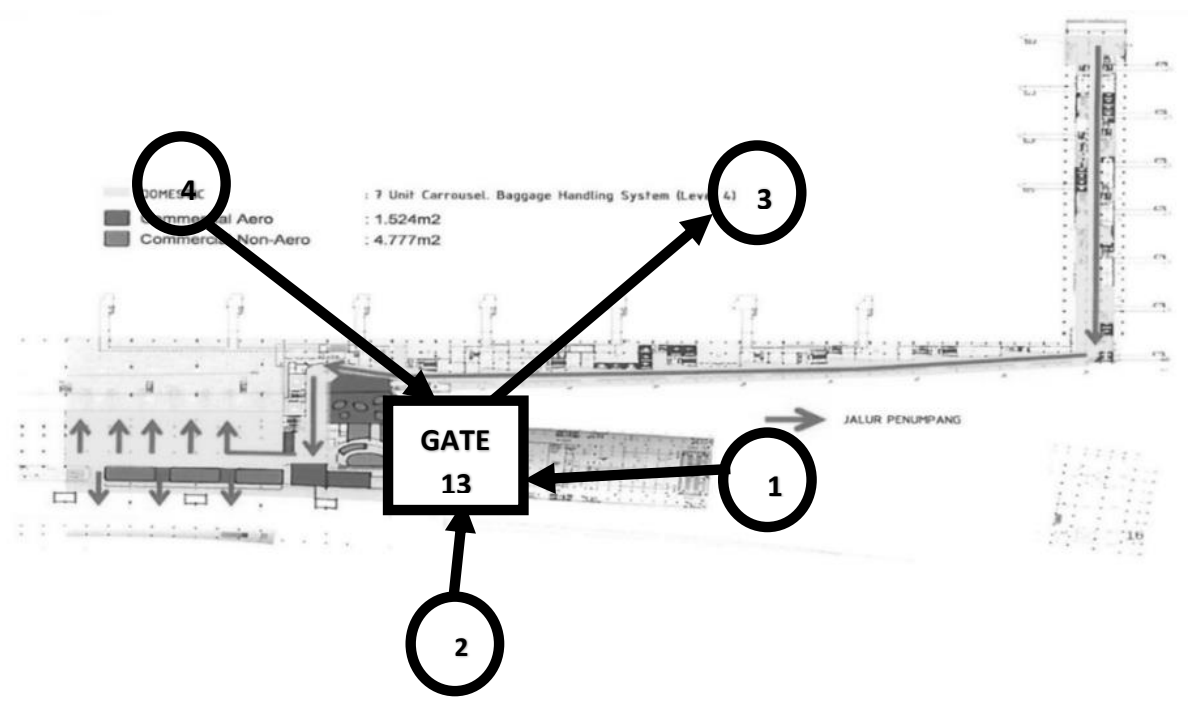

Figure 4.4. Passenger Flow in Gate 13.

In order to pass and will be stopped in the following condition:

1) If the scanner detected dangerous goods in the baggage, the conveyer will stop for further checking if it is allowed to be loaded to an aircraft or is prohibited.

2) The baggage cannot be too close to other baggage because the scanner need to scan the barcode in separated manner. If the baggage stick too close to each other, the conveyer will stop and a staff/porter need to put the baggage in a certain distance from other baggage. 
3) There are 4 levels of Baggage Handling System, in which each level is marked by a rubber gate. The rubber gate can only be passed by baggage that weigh more than 5 kilograms. Baggage less than 5 kilograms cannot pass the rubber gate.

4) The baggage that is being held down by rubber gate will overlap with the next baggage in the conveyer belt, causing the baggage being too close and stopping the conveyer at the next scanning process.

These conditions makes baggage transporting process longer in a baggage with the issue occurs and thus affecting the on-time performance of a flight.

\section{b. Passenger Flow}

Passenger flow is one crucial issue in the opening of Terminal 3, specifically Gate 13. Ideally, the flow of passenger need to be planned in the planning phase of building an airport so that there is no collision between flows of passengers. This is to ensure that there is no confusion and avoid queues and passenger density in one spot. However, in Terminal 3 Gate 13 There are four flow of passenger colliding.

Gate 13 in Terminal 3 have 2 floors. The first floor (Ground Floor) is used for passenger arrival, meaning passengers that have landed in Gate 13 will enter the terminal via arrival gate in the ground floor. The passenger bus to and from remote area and Garuda Indonesia International flights at Terminal $2 \mathrm{~F}$ is accessed from the ground floor of Gate 13. Transit passengers from international to domestic flights and vice versa is going through gate 13 as well. The first floor is used for passenger boarding to aircraft at Gate 13. Passenger that is using Gate 13 to board to their aircraft using Aerobridge is not colliding with the other passenger because they are boarding in the first floor. There is one meeting point for 4 flow in the ground floor of Gate 13 in Terminal 3. The passenger flows that collided in Gate 13 is shown in

\section{Figure 4.4.}

The flows of passenger that is colliding in the ground floor of Gate 13 in Terminal 3 Soerkarno-Hatta International Airport is as follows:

Flow 1: Arriving passenger from gate 13, 14, and 15

Flow 2: Passenger going to remote area

Flow 3: Transit passenger going to Terminal 2

Flow 4: Transit passenger from Terminal 2

In events where there are two or more flows meet in the ground floor of Gate 13 of Terminal 3, long queues of passenger will stack up and completely slowing down the passenger flow. There are not enough signage as well during the observation 
done by researcher causing confusion to passengers. This inefficient passenger flow explains the increase in airport delay in Terminal 3 or during the second half of 2016.

\section{Conclusion}

Based on observation in the field, The Garuda Indonesia displacement of domestic flights from Terminal $2 \mathrm{~F}$ to Terminal 3 in Soekarno-Hatta International Airport is proven as the cause of average on-time performance degradation of Garuda Indonesia in year 2016. There are several issues that is arising in SoekarnoHatta International Airport Terminal 3. The issues includes gate capacity gap, mismatched information in Flight Information Display System (FIDS), processes in Baggage Handling System (BHS), and collision of passenger flow due to the layout of the airport. This is showing the unpreparedness of Terminal 3 to be used for operations for Garuda Indonesia.

There are difference in the on-time performance of Garuda Indonesia between the first half of 2016 (January to June 2016) and the second half of 2016 (July to December 2016). The average on-time performance of Garuda Indonesia in the first half of 2016 is $91.16 \%$ and the average on-time performance in the second half is $85.14 \%$. The average on-time performance percentage in the whole year 2016 is $88.15 \%$ with the highest point in January 2016 at $93.50 \%$ and the lowest point in December 2016 at $79.36 \%$. Overall the year's on-time performance is still higher than Garuda Indonesia target on-time performance of $85 \%$. The degradation of ontime performance level spiked in August 2016 as well with on-time performance of $80.35 \%$.

Based on the data analysis, the biggest delay contributor to the domestic flights of Garuda Indonesia is airport delay. In the first half of 2016 (January to June 2016), airport delay contributed $49.56 \%$ of total delay in that period. While in the second half of 2016 (July to December 2016), airport delay contributed $60.30 \%$ of total delay in that period. Airport delay contributed a total of $56.56 \%$ of delay in the whole year of 2016. The highest number of airport delay occurred in December 2016 with 917 delays and August 2016 with 855 delays.

As for suggestions that can be offered to solve the problems, to keep the level of on-time performance high, Garuda Indonesia need to minimize the delays by controllable or internal factors such as commercial and station handling as these factors is easier to control than airport which is an external factor. For gate capacity 
problems, Garuda Indonesia need to have additional gates in Terminal 3 and the gate capacity should be increased when the terminal is ready. For discrepancies in FIDS, additional staff could be assigned to distribute the correct information in the station manually if system is not working properly. For baggage handling, as the time of baggage processing increase, Garuda Indonesia could propose an earlier check-in closing time from the original 30 minutes to approximately 45 minutes to compensate the baggage handling process. And the last, for collisions of passenger flow in Gate 13, one or more of the flows need to be transferred to other gates so that it does not meet on Gate 13.

\section{References}

Brunetta, L. and G. Romanin-Jacur (2004). "Passenger and Baggage Flow in an Airport Terminal: A Flexible Simulation Model.".

Duke, J. and V. Torres (2005). Multifactor Productivity change in the air transportation industry. Monthly Labor Review.

Glass, G. V. and K. D. Hopkins (1984). Statistical Methods In Education and Psychology, Pearson.

Lor, P. (2011). "International and Comparative Librarianship: Chapter 4."

Matsuo, S., et al. (2010). "Evaluation of Passenger Flow Lines in Airport Terminals."

Mills, M. (2006). "Comparative Research: Persistent Problems and Promising Solutions."

Neufville, R. d. and A. R. Odoni (2013). Airport Systems: Planning, Design, and Management, McGraw-Hill Education.

The Indonesia National Air Carriers Association (INACA), 2003 